\title{
A ESCRAVIDÃO CONTEMPORÂNEA EM ESPAÇOS RURAIS: UMA ABORDAGEM GEOGRÁFICA SOBRE OS APANHADORES DE CAFÉ NA MESORREGIÃO SUL/SUDOESTE DE MINAS
}

Glaucione Raimundo ${ }^{1}$

Ana Rute do Vale ${ }^{2}$

RESUMO: De acordo com dados da Secretaria do Trabalho, entre 2013 e 2019, foram resgatados 361 apanhadores de café escravizados no Sul/Sudoeste de Minas. As principais medidas estabelecidas pelo Estado para enfrentar esse crime se baseiam apenas na inclusão dos nomes de escravizadores na lista suja do trabalho escravo e na obrigatoriedade de pagamentos de multas e demais débitos trabalhistas às vítimas. Nesse sentido, o presente artigo buscou evidenciar a dinâmica socioeconômica na cafeicultura da mesorregião Sul/Sudoeste de Minas, as incidências do trabalho escravo contemporâneo nesse setor empregatício na região e as principais medidas tomadas pelo Estado no combate a esse grave problema socioeconômico. Os resultados mostraram que existem muitos retrocessos, que contraditoriamente vem sendo implementados pelo próprio Estado, como o corte de verbas no Ministério de Trabalho, que prejudica diretamente a atuação de auditores fiscais e a Reforma Trabalhista sancionada em 2017, que alterou a Consolidação das Leis de Trabalho, banalizando o que a própria legislação brasileira determina como trabalho escravo.

PALAVRAS - CHAVE: geografia agrária; trabalho escravo; cafeicultura; Minas Gerais; agronegócio.

\section{CONTEMPORARY SLAVERY IN RURAL AREAS: A GEOGRAPHICAL APPROACH TO COFFEE CATCHERS IN THE SOUTH/SOUTHWEST OF MINAS GERAIS}

ABSTRACT: According to data from the Department of Labor, between 2013 and 2019, 361 coffee catchers enslaved in the South/ Southwest of Minas Gerais were rescued. The main

\footnotetext{
${ }^{1}$ Mestranda do Programa de Pós-Graduação em Geografia da Universidade Federal de Alfenas MG. Bolsista da Fapemig.E-mail:glaucione.raimundo@sou.unifal-mg.edu.br

2 Professora do curso de Graduação e Pós-Graduação em Geografia da Universidade Federal de Alfenas - MG. E-mail: ana.vale@unifal-mg.edu.br
} 
measures established by the State to face this crime are based only on the inclusion of the names of enslavers in the dirty list of slave labor and on the mandatory payment of fines and other labor debts to victims. In this sense, this article sought to highlight the socioeconomic dynamics in coffee growing in the South/Southwest of Minas Gerais mesoregion, the incidences of contemporary slave labor in this sector employed in the region and the main measures taken by the State to combat this serious socioeconomic problem. The results showed that there are many setbacks, which contradictorily have been implemented by the State itself, such as the cutting of funds in the Ministry of Labor, which directly harms the performance of tax auditors and the Labor Reform sanctioned in 2017, which changed the Consolidation of Labor Laws, trivializing what Brazilian legislation itself determines as slave labor.

KEYWORDS: agrarian geography; slave labor; coffee growing; Minas Gerais; agribusiness.

\section{ESCLAVITUD CONTEMPORÁNEA EN ZONAS RURALES: UN ENFOQUE GEOGRÁFICO DE LOS CAPTADORES DE CAFÉ EN EL SUR/SUROESTE DE MINAS GERAIS}

RESUMEN: Según datos del Departamento de Trabajo, entre 2013 y 2019, 361 captadores de café esclavizados en el sur/suroeste de Minas Gerais fueron rescatados. Las principales medidas establecidas por el Estado para enfrentar este delito se basan únicamente en la inclusión de los nombres de los esclavizadores en la lista sucia de trabajo esclavo y en el pago obligatorio de multas y otras deudas laborales a las víctimas. En este sentido, este artículo buscó resaltar la dinámica socioeconómica del cultivo de café en el sur/suroeste de la mesorregión de Minas Gerais, las incidencias de la mano de obra esclava contemporánea en este sector empleado en la región y las principales medidas adoptadas por el Estado para combatir este grave problema socioeconómico. Los resultados mostraron que hay muchos retrocesos, que contradictoriamente han sido implementados por el propio Estado, como el recorte de fondos en el Ministerio de Trabajo, que perjudica directamente el desempeño de los auditores fiscales y la Reforma Laboral sancionada en 2017, que cambió la Consolidación de las Leyes Laborales, trivializando lo que la propia legislación brasileña determina como trabajo esclavo.

PALABRAS CLAVE: geografía agraria; trabajo esclavo; la producción de café; Minas Gerais; agronegocio.

INTRODUÇÃO

O trabalho escravo contemporâneo é uma conduta ilícita que afeta as 
condições de vida e de trabalho de suas vítimas, sendo uma estratégia utilizada por muitos empregadores para a garantia de maior lucratividade em suas empresas ou propriedades (SAKAMOTO, 2020). Os meios para se alcançar essa submissão trabalhista se caracterizam na privação da liberdade a partir de mecanismos de endividamento, uso da força (assassinatos, espancamentos por proprietários e funcionários) e outras formas de intimidações. Além dessas estratégias de sujeições, as retenções de documentos, recrutamento e isolamento geográfico também podem caracterizar a escravidão contemporânea (CAVALCANTI, 2020).

A escravidão contemporânea pode ser encontrada em diferentes setores empregatícios brasileiros: na construção civil, no comércio varejista, na pecuária, no cultivo de café, na produção de carvão vegetal, dentre tantas outras atividades (PORTAL DE INSPEÇÃO DO TRABALHO- RADAR SIT, 2021).

Mais especificamente na cafeicultura da mesorregião Sul/Sudoeste de Minas, região responsável pela produção de 30,4\% de sacas de café nacionalmente (CONAB, 2020), tem surgido muitas denúncias sobre trabalho escravo durante o período das colheitas, sendo as vítimas denominadas como os apanhadores de café, oriundas majoritariamente de regiões brasileiras mais pobres.

Muitos dos casos denunciados na região - a cada safra de café - costumam ser divulgados em reportagens e essas delações fazem com que o Ministério Público do Trabalho tome as devidas providências jurídicas (cobranças de multas e demais débitos trabalhistas). No entanto, tudo indica que a morosidade na aplicação da pena incentiva a exploração desses trabalhadores, pois existe um grande abismo que separa a lei e a sua aplicabilidade na realidade.

Além disso, a situação das vítimas desta exploração pode se tornar pior com a pandemia de Covid-19, doença causada pelo coronavírus (Sars-Cov-2). Apesar da obrigatoriedade de ações para a prevenção da doença (o distanciamento 
social, o uso de máscaras e a higienização com álcool em gel), o aliciamento e as migrações destas vítimas estão ocorrendo livremente na colheita da safra, ainda que em menor intensidade.

Dessa forma, esse trabalho acadêmico se propõe a evidenciar a dinâmica da cafeicultura no Sul/Sudoeste de Minas, as incidências do trabalho escravo contemporâneo na cafeicultura da mesorregião e principais medidas tomadas pelo Estado no combate a esse grave problema socioeconômico.

Para o desenvolvimento desse trabalho utilizou-se como procedimentos metodológicos: revisão bibliográfica referentes aos temas geografia, questão agrária e trabalho escravo contemporâneo na cafeicultura, levantamento de dados estatísticos e pesquisa documental, utilizando como fonte de pesquisa, as plataformas IBGE (Instituto Brasileiro de Geografia e Estatística), Secretaria do Trabalho, Ministério da Economia e Portal de Inspeção do Trabalho - Radar SIT, CONAB (Companhia Nacional de Abastecimento), CECAFÉ (Conselho dos Exportadores de café do Brasil), Balança Comercial do Agronegócio Brasileiro e os canais midiáticos Brasil de Fato, Portal G1- Sul de Minas e EPTV - Sul de Minas.

Além da introdução, esse trabalho se estrutura a partir da caracterização da área de estudo, seguida pela explicação a respeito da dinâmica socioeconômica da cafeicultura no Sul/Sudoeste de Minas, depois, como se caracteriza o trabalho escravo contemporâneo na região e, por fim, discute o papel representado pelo Estado no combate a esse tipo de escravidão contemporânea.

\section{ÁREA DE ESTUDO}

O Sul/Sudoeste de Minas é uma das 12 mesorregiões do estado de Minas Gerais, composta por 146 municípios e 10 microrregiões (Figura 1), possuindo uma população de 2.438.611 habitantes, de acordo com o Censo Demográfico do 
IBGE (2010). Esta mesorregião possui grande destaque em produções agrícolas, principalmente na cafeicultura, atividade de grande importância socioeconômica que ocupa uma elevada densidade de trabalho manual no cultivo e colheita de grãos, devido aos relevos acidentados da região que impossibilitam que cafeicultores utilizem uma agricultura mais mecanizada em suas lavouras (VILELA; RUFINO, 2010).

De acordo com Silva, Santos e Lima (2001), a evolução do sistema agroindustrial (conhecido hoje como agronegócio) na região, se justifica pela territorialização de cooperativas e demais empresas do ramo; pela possibilidade de financiamentos e assistência técnica aos cafeicultores; pelo aumento de preços internacionais e de exportações e pela renovação da atividade agrícola através de apoios governamentais. Todos esses fatores propiciaram o aumento de áreas plantadas por hectares, fazendo com que a região se tornasse competitiva na produção dessa commodity.

Figura 1 - Mapa de localização geográfica da Mesorregião Sul/Sudoeste de Minas Gerais. 


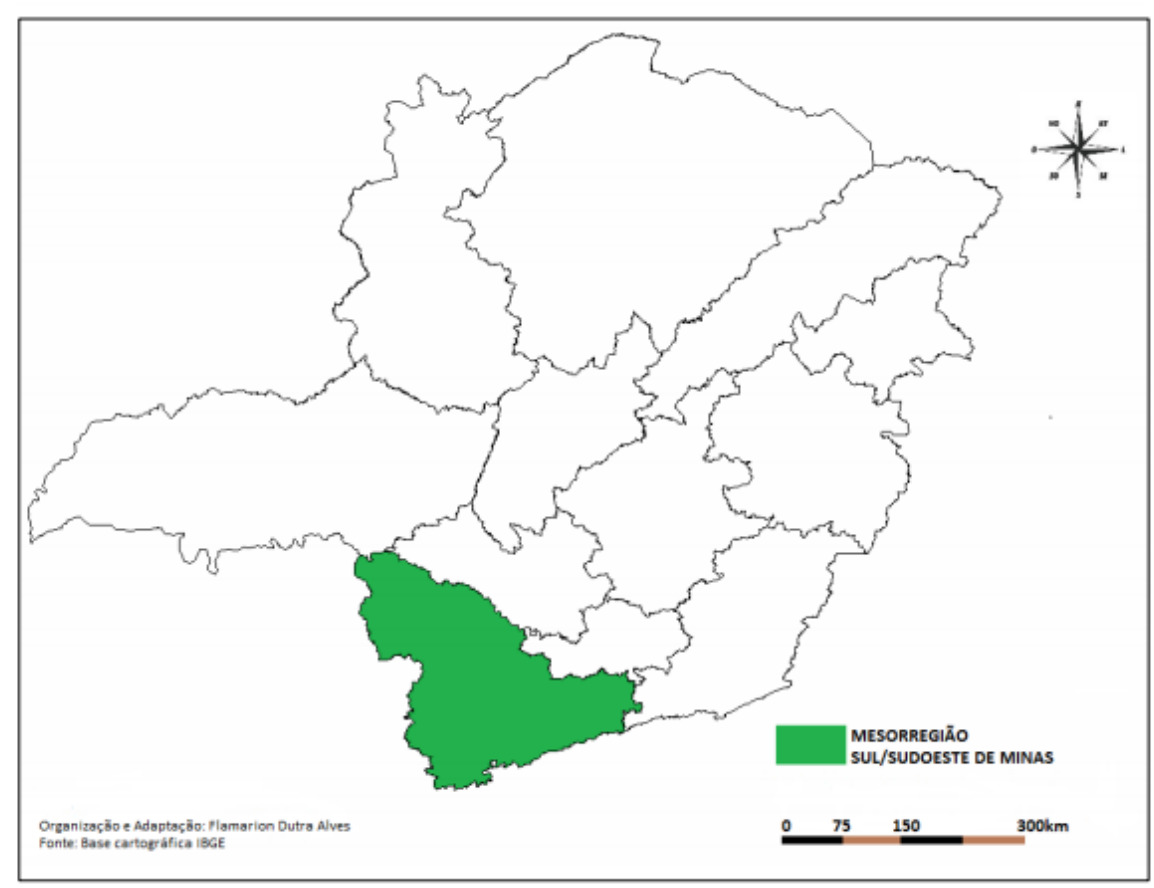

Fonte: ALVES (2016).

\section{A DINÂMICA SOCIOECONÔMICA DA CAFEICULTURA NO SUL/SUDOESTE DE MINAS} GERAIS

Para Oliveira (2016) a mundialização da agricultura integra territórios em uma rede mundial do agronegócio, criando e reordenando novas dinâmicas socioespaciais aos lugares em que se insere.

A monopolização do território é desenvolvida pelas empresas de comercialização e/ou processamento industrial da produção agropecuária, que sem produzir no campo, controlam através de mecanismos de subordinação, camponeses e capitalistas produtores do campo. As empresas monopolistas atuam como players no mercado futuro das bolsas de mercadorias do mundo, e, às vezes controlam a produção dos agrotóxicos e fertilizantes. (OLIVEIRA, 2016, p. 233).

Alves (2019) mencionando em sua pesquisa Raffestin (1993 apud Alves, 2019) afirma que as regiões ocupadas pelo agronegócio se desenvolvem a partir 
de territorialidades do poder, assumindo novas formas materiais e imateriais.

Dessa forma, será a partir do dinamismo da mundialização e modernização da agricultura que ocorrerá a territorialização de empresas agrícolas e demais serviços em diferentes regiões do mundo, onde o território (apropriado pelo capital) desenvolverá novas maneiras de ocupação do solo e também novas relações sociais, sobretudo, na categoria trabalho.

A produção de café no Brasil se insere ao contexto da mundialização e modernização da agricultura, onde o país é responsável por 36,6 \% da produção mundial dessa commodity, o que faz com que essa produção agrícola ocupe o $6^{\circ}$ lugar nas exportações brasileiras mais significativas (CONAB, 2020; BALANÇA COMERCIAL DO AGRONEGÓCIO BRASILEIRO, 2021).

As exportações brasileiras de sacas de café, em junho de 2021, foram de 3.012 milhões de sacas de $60 \mathrm{~kg}$, gerando $U \$ \$ 23$ milhões ao país. Com esse desempenho, o Brasil alcançou um novo recorde no fechamento das remessas de café na safra de 2020/21, com um acúmulo de 45. 599 milhões de sacas, alcançando um crescimento de 13,3\% do que em relação à safra de 2019/ 20 e uma alta de 10,1\% sobre a produção das 41.426 milhões de sacas da safra de 2018/19, que era até então o maior desempenho produtivo conquistado nos últimos anos (CECAFÉ, 2021).

As produções totais de café nas regiões brasileiras, em 2020, alcançaram um total de 63 milhões de sacas de café beneficiadas (Gráfico 1). Em termos de variedade, a produção café arábica atingiu 48,77 milhões de sacas, enquanto a de conilon foi de 14,31 milhões de sacas (CONAB, 2020).

Gráfico 1 - Produção de café total (arábica e conilon) nas regiões brasileiras em 2020 


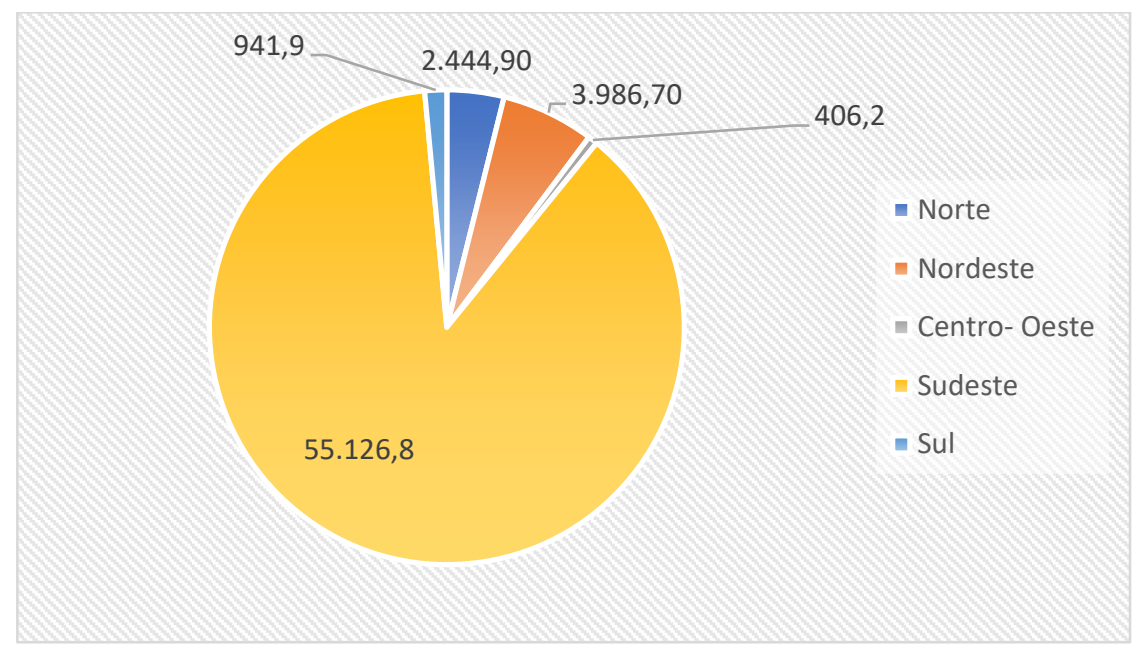

Fonte: Conab (2020, p. 21). Org.: RAIMUNDO e VALE (2021).

A região Sudeste ocupou a primeira posição como produtora de café do país, em 2020, com a produção de 55,15 milhões de sacas de café, com o crescimento produtivo de 29,2\% à safra anterior (gráfico 1). Em relação ao ranking produtivo de café na região, o estado de Minas Gerais ocupou o primeiro lugar, com a produção de cerca de 34,64 milhões de sacas, com o crescimento produtivo de 41,1\%, na safra de 2020 (Tabela 1).

Tabela 1 - Produção de sacas de café total (arábica e conilon) na região Sudeste do Brasil, entre 2019 e 2020.

\begin{tabular}{c|c|c|c}
\hline Sudeste brasileiro & 2019 & 2020 & \multirow{2}{*}{ V\% } \\
\cline { 2 - 3 } & Sacas & Sacas & \multirow{2}{*}{} \\
\hline Minas Gerais & $24.553,6$ & $34.647,1$ & 41,1 \\
\hline Rio de Janeiro & 245,0 & 371,0 & 51,4 \\
\hline Espírito Santo & $13.498,0$ & $13.958,0$ & 3,4 \\
\hline São Paulo & $4.339,5$ & $6.180,7$ & 42,4 \\
\hline Total & $42.636,1$ & $55.126,8$ & $29,2 \%$ \\
\hline
\end{tabular}

Fonte: Conab (2020, p 21.). Org.: RAIMUNDO e VALE (2021).

No contexto da cadeia produtiva do estado de Minas Gerais, a mesorregião 
Sul/Sudoeste de Minas ocupou o primeiro lugar em 2020, com a produção de cerca de 19,15 milhões de sacas, alcançando um incremento de 37\% em relação à safra anterior (Tabela 2).

Tabela 2 - Produção de café total (arábica e conilon) em Minas Gerais entre os anos 2019 e 2020.

\begin{tabular}{c|c|c|c}
\hline Mesorregiões & 2019 & 2020 & V\% \\
\hline Sul e Sudoeste & $13.978,8$ & $19.152,2$ & 37,0 \\
\hline Triângulo, Alto Parnaíba e Noroeste & $4.591,9$ & $6.000,8$ & 30,7 \\
\hline Zona da Mata, Rio Doce e Central & $5.354,2$ & $8.791,0$ & 64,2 \\
\hline Norte, Jequitinhonha e Mucuri & 628,7 & 703,1 & 11,8 \\
\hline Total & $24.553,6$ & $34.647,1$ & 41,1 \\
\hline
\end{tabular}

Fonte: Conab (2020, p. 21). Org.: RAIMUNDO e VALE (2021).

As mesorregiões Triângulo Mineiro, Alto do Parnaíba e Noroeste ocuparam o segundo lugar da cadeia produtiva do estado, com a produção de cerca de 6.000 mil sacas de café beneficiadas, alcançando um aumento produtivo de 30,7 \% em relação à colheita anterior, seguidas pela Zona da Mata, Rio Doce e Central, que produziram cerca de 8.790 mil sacas de café, com incremento de $64,2 \%$ e o Norte de Minas, Jequitinhonha e Mucuri, que produziram 703 mil sacas de café, alcançando o crescimento em sua produção de $11,8 \%$ em relação a temporada passada.

Dentre as regiões mineiras responsáveis pela produção cafeeira, o Sul/ Sudoeste de Minas vem se destacando como responsável por produzir mais de $55,2 \%$ do rendimento dessa commodity, através de uma estrutura organizacional e espacial à serviço do mercado nacional e também internacional (CONAB, 2020).

A inclusão da mesorregião no mercado competitivo do agronegócio do café ocorreu através da modernização no processo produtivo dessa atividade agrícola, “com parcerias de produtores com as empresas fornecedoras de insumos 
(adubos, fertilizantes e nutrientes para o solo) e indústrias transformadoras da matéria-prima" (VALE; CALDERARO; FAGUNDES, 2014, p. 9).

Os cultivos de lavouras de café na região ocupam extensivas e contínuas áreas de plantio e de formação. De acordo com Alves (2019), essas significativas áreas de produção se justificam por três fatores: a) - pelo aumento da procura dessa commodity no mercado mundial que incentiva regiões produtoras de café a aumentarem as suas áreas de plantio para maior colheita; b) - pela ação de cooperativas para a monopolização do território e c) - pelo arrendamento e venda de terras da agricultura familiar para o agronegócio. Para o geógrafo, vem ocorrendo "numa conjuntura global, a ascensão do capital externo na cafeicultura, que vem ganhando espaço em empresas multinacionais e territorializando no Sul de Minas" (p. 315).

Além disso, também contribuíram para a expansão produtiva dessa atividade no Sul/Sudoeste de Minas, sobretudo no pós-década de 1970, os seguintes fatores: a "existência de financiamentos, assistências técnicas, introdução de novas tecnologias, o aumento das exportações, o aumento dos preços internacionais e a renovação a cafeicultura via apoio governamental" (SILVA; SANTOS; LIMA, 2001, p. 9).

No século XXI, a região se destaca, principalmente, por reunir

[...] grande diversidade de sistemas técnicos e organizacionais vinculados à cafeicultura. Nenhuma outra região possui tantas cooperativas, órgãos estatais, centros de pesquisa e extensão rural, armazéns, corretores, transportadores, beneficiadores, certificadores, consultores, exportadores, bancos de crédito, eventos e feiras dedicados ao café. A região possui também uma Estação Aduaneira do Interior (Eadi), localizada na cidade de Varginha, criada com o intuito principal de exportar a produção de café da região (FREDERICO, 2014).

Outro fator que deve ser levado em consideração é a implantação de cursos 
superiores e técnicos voltados para a agropecuária, agricultura, cafeicultura e produções de alimentos, dentre outros cursos que se relacionam a dinâmica produtiva do campo em Institutos Federais de Educação e Tecnologia-Sul de Minas, alocados nos municípios Inconfidentes, Poços de Caldas, Machado, Muzambinho Passos e Pouso Alegre (ALVES, 2019).

Em relação a área colhida em lavouras de café (por hectares) na região, dados do IBGE - Produção Agrícola Municipal (2021) evidenciam que a área colhida (por hectares) entre os anos de 1990 a 2019, manteve-se de certa forma, constante, com baixas variações percentuais, menos de $2 \%$ ao longo dos anos analisados, o que demonstra a grande relevância dessa atividade agrícola para a região (Tabela 3).

Tabela 3 - Área colhida de lavouras permanentes e de lavouras de café, em hectares na mesorregião Sul/Sudoeste de Minas Gerais (1990- 2019)

\begin{tabular}{c|c|c|c}
\hline Anos & $\begin{array}{c}\text { Área colhida de lavouras } \\
\text { permanentes }\end{array}$ & $\begin{array}{c}\text { Área colhida de lavouras de } \\
\text { café }\end{array}$ & (\%) \\
\hline 1990 & 421.974 & 404.814 & 95.93 \\
\hline 2000 & 430.102 & 414.308 & 96.32 \\
\hline 2010 & 450.595 & 432.293 & 95.93 \\
\hline 2019 & 440.253 & 416.486 & 94.60 \\
\hline
\end{tabular}

Fonte: Produção Agrícola Municipal - IBGE (2021). Org.: RAIMUNDO e VALE (2021).

As informações na tabela também expõe a predominância do cultivo do café em relação às outras culturas agrícolas permanentes, o que também indica a existência de uma organização socioeconômica direcionada à produção de lavouras de café na região, não apenas no campo, mas também na cidade (principalmente nas médias e pequenas), onde a dependência produtiva atrai cada vez mais empresas especializadas nesse setor econômico em espaços urbanos dos municípios da região para atender as necessidades produtivas do 
campo.

Em decorrência do forte agronegócio do café e a tecnologia aplicada ocorre uma imposição nos moldes urbanos regionais visando atender as necessidades do campo, ou seja, uma reestruturação territorial regional a partir da especialização econômica para a produção cafeeira. Com isso, ocorreu uma dependência econômica aos arranjos produtivos do campo, e o surgimento de empresas grandes com capital vinculado a este ramo econômico (SANTOS, 2011 apud VALE; CALDERARO; FAGUNDES, 2014, p. 10).

As áreas destinadas à colheita com maiores destaques nas microrregiões da mesorregião Sul/Sudoeste de Minas, entre os anos de 1990 a 2019, se concentram nos municípios de Alfenas, São Sebastião do Paraíso e Varginha (Tabela 4). Neles estão alocados "armazéns de cafés, cooperativas, pontos de comercializações internacionais ligados ao transporte de grãos de café para o porto de Santos, bem como instituições de pesquisa e apoio técnico para produtores da região" (ALVES, 2019, p. 317).

Tabela 4 - Áreas destinadas à colheita de café (hectares) nas microrregiões do Sul/ Sudoeste de Minas entre 1990 a 2019

\begin{tabular}{c|c|c|c|c}
\hline Microrregião & 1990 & 2000 & 2010 & 2019 \\
\hline Alfenas & 58.555 & 74.947 & 65.121 & 71.538 \\
\hline Andrelândia & 789 & 798 & 567 & 456 \\
\hline Itajubá & 5.146 & 3.676 & 3.987 & 2.518 \\
\cline { 1 - 1 } Passos & 46.334 & 29.131 & 31.138 & 45.041 \\
\hline Poços de Caldas & 46.384 & 57.120 & 47.692 & 44.419 \\
\hline Pouso Alegre & 4.589 & 5.872 & 5.248 & 4.314 \\
\hline Santa Rita do & 22.663 & 28.970 & 37.030 & 28.928 \\
Sapucaí & & & & \\
\hline
\end{tabular}




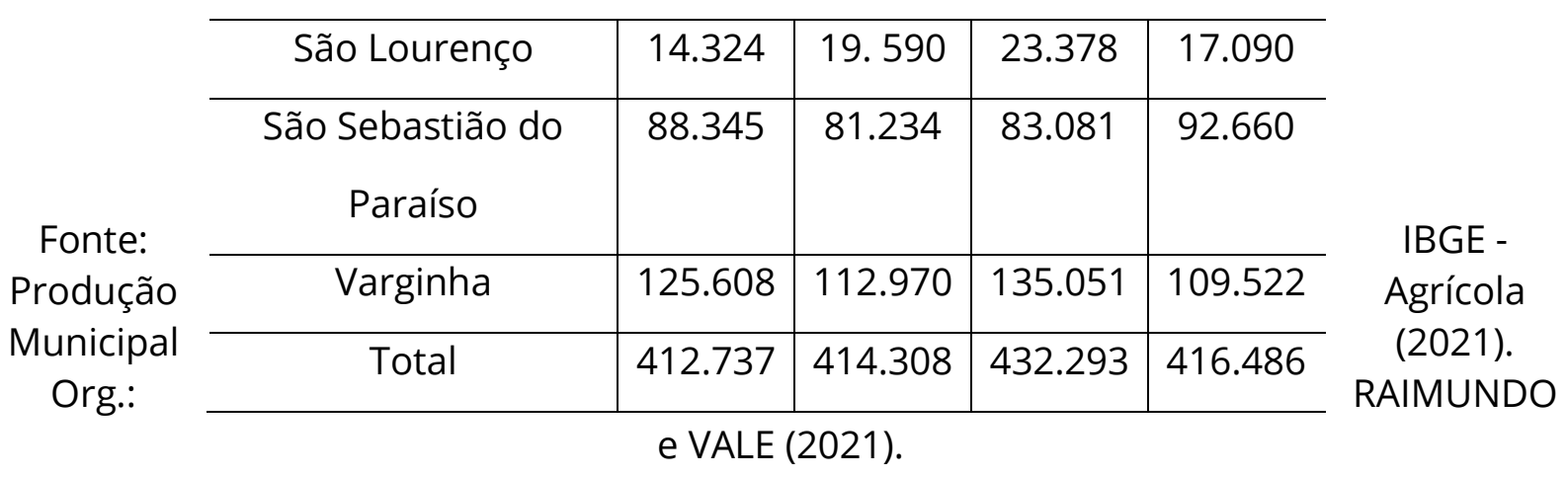

Ressalta-se que alguns municípios das microrregiões de Alfenas e Varginha estão no grupo dos 34 municípios que foram atingidos pela inundação provocada pela implantação da usina hidrelétrica de Furnas que, no final da década de 1950, cobriu uma superfície de $1.440 \mathrm{Km}^{2}$, configurando um perímetro de $3.500 \mathrm{~km}$ da área, com uma bacia de drenagem com área total de $54.464 \mathrm{Km}^{2}$, formando um dos maiores lagos artificiais do mundo. A formação do lago (ou reservatório) de Furnas se deu a partir de dois "braços": a leste, o rio Grande (240 km de extensão) e ao sul, junção dos rios Verde, Sapucaí e Machado (LEMOS JÚNIOR, 2010).

A inundação da várzea alterou a dinâmica produtiva de muitos agricultores familiares e grandes produtores da região, sobretudo da microrregião de Alfenas, que antes da inundação se dedicavam ao cultivo do arroz, milho e alho. No pósdécada de 1970, com a inserção do cultivo de café na região foi alterada a dinâmica espacial e socioeconômica de muitos municípios, dentre eles Alfenas e Areado, com a inserção de novas rodovias e empresas voltadas para a produção, manutenção e escoamento do café na região e em diferentes partes do país e do mundo (VALE, 2017).

A produção cafeeira do Sul/Sudoeste de Minas caracteriza-se pela presença de grandes, médios e pequenos produtores, que contam com o apoio de diversas cooperativas para dar assistência técnica e extensão rural, armazenamento de grãos, financiamento e crédito dentre elas 
Ltda.), a COOCATREL (Cooperativa dos Cafeicultores da Zona de Três Pontas Ltda.), Minasul (Cooperativa dos Cafeicultores da Zona de Varginha Ltda.), a COOPARAísO (Cooperativa Regional de Cafeicultores em São Sebastião do Paraíso Ltda.) e a COOPFAM (Cooperativa dos Agricultores Familiares de Poço Fundo e Região) que como particularidade, produz café orgânico - dentre outras cooperativas, empresas e instituições de beneficiamento cafeeiro (VALE; CADERARO; FAGUNDES, 2014, p. 9).

Em relação ao processo de comercialização, as sacas de café colhidas em fazendas da região são levadas a essas cooperativas, onde podem ficar estocadas por meses para a comercialização. As negociações dessas sacas na região para o exterior são realizadas em pontos comerciais conhecidos como Recintos de Exportação, alocados nos municípios Guaxupé, Varginha e Poços de Caldas (ALVES, 2019). As negociações internacionais e o embarque dessas sacas para o exterior são realizados pela Trading Exportadoras, onde após receberem a carga em seus países distribuem o produto no mercado interno. Além da exportação, indústrias torrefadoras locais e de outros estados brasileiros costumam beneficiar o grão para a produção do café moído para o consumo em supermercados (RÉPORTER BRASIL, 2019).

Como já mencionado, a cafeicultura na região ocupa uma elevada densidade de trabalho manual no cultivo de grãos, devido aos relevos acidentados que impossibilitam cafeicultores de utilizarem uma agricultura mais mecanizada em suas lavouras (VILELA; RUFINO, 2010). As contratações de trabalhadores na cafeicultura da região costumam ocorrer no período da safra, sobretudo, na colheita do café.

Os trabalhadores contratados possuem origens variadas, podendo ser da região ou de fora dela, geralmente do Norte de Minas, Norte do Paraná e da Bahia, contratados por "gatos" em suas regiões de origem. O pagamento é realizado a partir da quantidade de café colhido, ou seja, por produção, sendo uma forma encontrada pelos proprietários para o aumento da produção de apanhadores de 
café na lavoura. Essa forma de remuneração é nociva pelo fato de transferir ao funcionário o controle de sua produção que se relaciona diretamente ao seu ganho. Sendo assim, quanto mais baixo for o salário do apanhador, maior será o incentivo à produção. Tal forma de pagamento pode contribuir para o desgaste físico dos trabalhadores envolvidos, assim como o aparecimento de diversas doenças físicas (COALIZAÇÃO DO CAFÉ, 2004).

É a partir das contratações de mão de obra oriundas de regiões mais pobres, que se manifestam duas questões problemáticas da cafeicultura no Sul/Sudoeste de Minas: a precarização do trabalho na cafeicultura e o trabalho escravo contemporâneo. A desvalorização do trabalho de apanhadores de café com o aumento exorbitante do trabalho informal e exploratório e as más condições no ambiente de trabalho a que estão expostos, é o que fortalece ainda mais o uso da mão de obra escrava neste setor empregatício da região em pleno século XXI.

\section{O TRABALHO ESCRAVO NA CAFEICULTURA NO SUL/SUDOESTE DE MINAS}

A escravidão contemporânea em lavouras de café no Sul/ Sudoeste de Minas tende a ser alimentada por diferentes empresas do ramo, dentre elas grandes corporações, empresas torrefadoras e de solúveis, pois o que importa para essas instituições é apenas uma matéria-prima de qualidade, barata e que promova lucratividade (SILVEIRA; MARQUES, 2009).

O trabalho escravo contemporâneo na cafeicultura na região é um fenômeno que costuma ser denunciado por sindicatos, mídias e demais órgãos representativos de trabalhadores rurais. Dados referentes ao cadastro nacional da "Lista Suja" do Trabalho Escravo Contemporâneo (Secretaria do Trabalho, 2018; 2019; 2020), evidenciam que entre os anos de 2013 a 2019, foram resgatados 361 trabalhadores no período da safra em cafezais da região (Figura 2). 
Figura 2 - Mapa dos municípios notificados com trabalho escravo na cafeicultura no Sul/Sudoeste de Minas Gerais de 2013 a 2019.

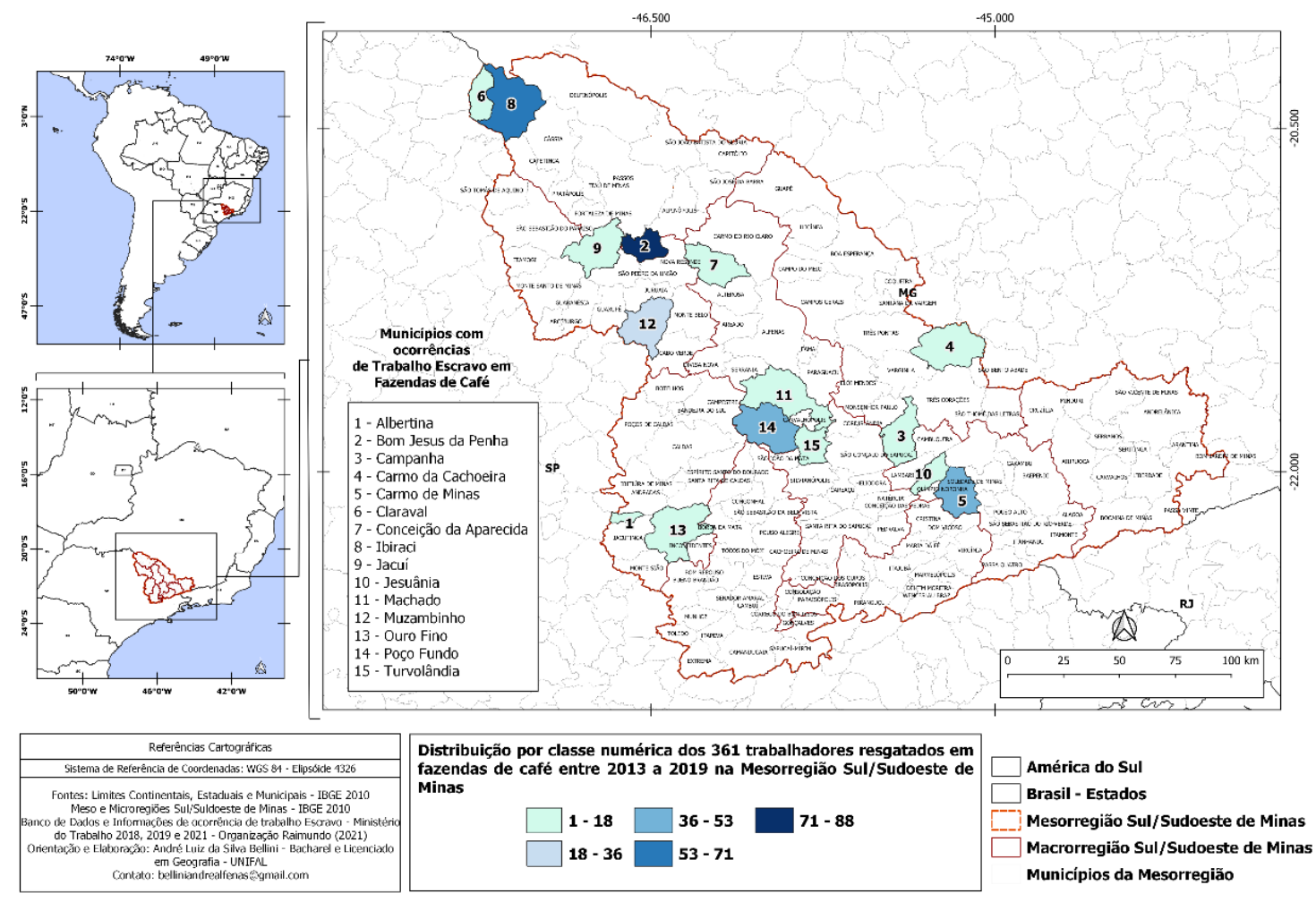

Fonte: Secretaria do Trabalho (2018; 2019; 2020). Mapa elaborado por André Luiz Bellini (2021).

Na Figura 2, foram mapeados os 15 municípios da mesorregião Sul/Sudoeste de Minas notificados pela Secretaria do Trabalho $(2018 ; 2019 ; 2020)$ com ocorrências de trabalho escravo na cafeicultura dentre os anos de 2013 a 2019, sendo eles: Albertina, Bom Jesus da Penha, Campanha, Carmo da Cachoeira, Carmo de Minas, Claraval, Conceição da Aparecida, Ibiraci, Jacuí, Jesuânia, Machado, Muzambinho, Ouro Fino, Poço Fundo e Turvolândia. Os municípios com maiores ocorrências de casos nos últimos anos foram os de Bom Jesus da Penha, (88) Ibiraci (62) e Poço Fundo (44) (Tabela 5).

Os dados coletados também demonstraram que a incidência da escravidão contemporânea na cafeicultura pode ocorrer em mais de uma propriedade rural nos municípios notificados em um único ano ou então em menos de um ano. Esse 
é o caso de Ibiraci, onde em 2014, foram resgatados 57 trabalhadores em propriedades distintas, de Bom Jesus da Penha, com o resgaste de 74 vítimas, em 2015, e com a reincidência de casos em 2016, enmvolvendo 14 trabalhadores em diferentes estabelecimentos e de Poço Fundo, com um total de 12 trabalhadores resgatados em 2015, em apenas uma propriedade e a reincidência de casos de escravidão em 2016, em duas novas propriedades, envolvendo 32 trabalhadores.

Tabela 5 - Trabalhadores escravizados em fazendas de café na mesorregião Sul/Sudoeste de Minas Gerais de 2013- 2019

\begin{tabular}{l|l|c}
\hline Anos & \multicolumn{1}{|c|}{ Municípios } & $\begin{array}{c}\text { Trabalhadores } \\
\text { Resgatados }\end{array}$ \\
\hline 2013 & Campanha & 1 \\
\hline 2014 & Ibiraci & 33 \\
\hline 2014 & Ibiraci & 13 \\
\hline 2014 & Ibiraci & 11 \\
\hline 2015 & Carmo de Minas & 22 \\
\hline 2015 & Carmo de Minas & 19 \\
\hline 2015 & Bom Jesus da Penha & 60 \\
\hline 2015 & Bom Jesus da Penha & 14 \\
\hline 2015 & Poço Fundo & 12 \\
\hline 2015 & Machado & 14 \\
\hline 2015 & Carmo da Cachoeira & 07 \\
\hline 2016 & Claraval & 13 \\
\hline 2016 & Machado & 04 \\
\hline 2016 & Bom Jesus da Penha & 14 \\
\hline 2016 & Poço Fundo & 12 \\
\hline 2016 & Poço Fundo & 20 \\
\hline 2016 & Conceição da Aparecida & 16 \\
\hline 2016 & Jesuânia & 10 \\
\hline 2017 & Jacuí & 14 \\
\hline 2017 & Albertina & 07 \\
\hline 2018 & Turvolândia & 01 \\
\hline 2018 & Muzambinho & 15 \\
\hline 2018 & Ibiraci & 05 \\
\hline 2019 & Ouro Fino & 17 \\
\hline 2019 & Turvolândia & 07 \\
\hline Total & & 361 \\
\hline & &
\end{tabular}


Fonte: Ministério do Trabalho $(2018,2019,2020)$ Org.: RAIMUNDO e VALE ( 2021).

Dentre as violações mais comuns às quais as vítimas do trabalho escravo em cafezais da região são submetidas destacam-se "alojamentos precários retenção de documentos pelos fazendeiros, além da própria falta de registro na carteira de trabalho" (CONECTAS DIREITOS HUMANOS, 2018, n. p.). Tais condições que degradam a vida e o trabalho de migrantes na região, são ilustradas por três reportagens publicadas nos sites eletrônicos Brasil de Fato (2018), Portal G1-Sul de Minas (2020) e EPTV-Sul de Minas (2021).

Na primeira reportagem, de autoria da jornalista Dotta (2018), é retratada uma operação que resgatou 15 apanhadores de café escravizados em uma propriedade rural no município de Muzambinho. Além do péssimo aspecto da moradia, a higiene, a alimentação e as condições de descanso desses trabalhadores eram subumanas (Figura 3). A reportagem mostra o relato de um dos jovens entre os escravizados nessa fazenda, que alegou ter ficado sem se alimentar por 3 dias, juntamente aos seus demais companheiros da casa, pois o dono da fazenda não disponibilizou o fogão, o gás e muito menos alimentos, descumprindo o que havia sido tratado entre ambas as partes. Esses trabalhadores ainda foram obrigados a comprarem seus instrumentos de trabalho (colheitadeira manual e gasolina para abastecê-la) e ainda foram vítimas de roubo de produção, um método no qual o fiscal não anota corretamente a quantidade de café colhida pelo trabalhador, fazendo com que ele receba menos por produção, beneficiando, assim, o empregador.

Figura 3 - Alojamento de apanhadores de café resgatados em uma propriedade rural no município de Muzambinho-MG, em 2018. 


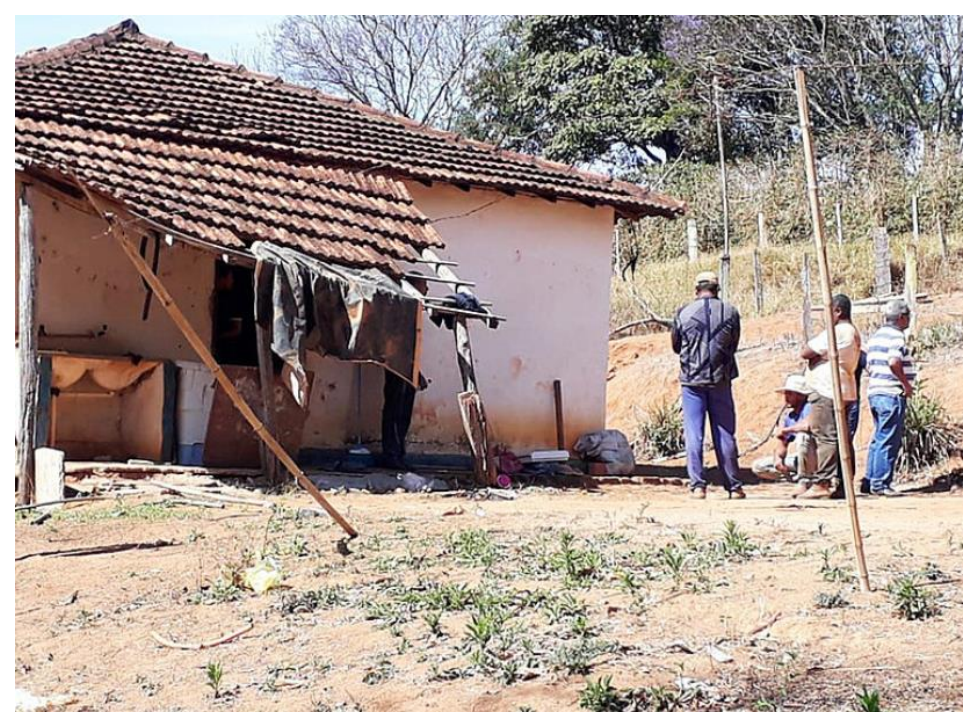

Fonte: DOTTA (2018).

Essa condição se assemelha ao que estava sendo enfrentado por 13 trabalhadores em uma fazenda de café no município de Machado, em julho de 2020, resgatados em uma operação realizada pela Polícia Federal e pelo Ministério Público do Trabalho, conforme foi publicado no Portal G1-Sul de Minas. Segundo a reportagem, nesse estabelecimento rural, os apanhadores de café exerciam suas funções sem o registro na carteira, sem uma remuneração justa e equipamentos de proteção individual, além de viverem em alojamentos precários, sem nenhuma estrutura de descanso, com colchões sujos e sem roupas de cama que se adequavam ao clima do município (Figura 4).

Figura 4 - Alojamento de apanhadores de café resgatados em uma propriedade rural no município de Machado-MG, em 2020. 


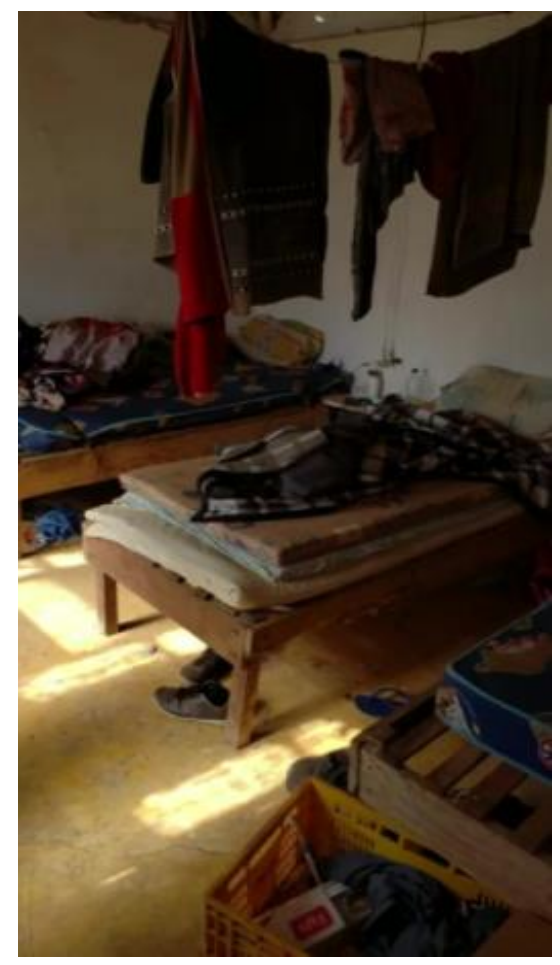

Fonte: Portal G1-Sul de Minas (2020).

Além das condições degradantes de vida e trabalho, muitos trabalhadores ainda são obrigados a arcarem com despesas (passagens, alimentação e demais gastos), antes mesmo de chegarem ao local de trabalho, como é o caso dos 63 apanhadores de café resgatados em 3 propriedades rurais nos municípios de Boa Esperança e Ilicínea, em julho de 2021, conforme demonstrou a reportagem da EPTV-Sul de Minas. Em Boa Esperança, foram resgatados 30 trabalhadores, enquanto que em Ilicínea, 9 trabalhadores foram libertados em uma propriedade e 24, em outra. Nesse caso, as vítimas são naturais de municípios da Bahia e tiveram que arcar com gastos de passagens de ônibus e alimentação. Em nenhuma das fazendas notificadas foram encontrados materiais de primeiros socorros e muito menos um encanamento que fornecesse água potável aos apanhadores (Figura 5). Além disso, os trabalhadores não possuíam registro na carteira e muito menos uma remuneração mensal.

Figura 5 - Alojamento de apanhadores de café resgatados em uma operação 
da Polícia Federal em uma propriedade rural no Sul de Minas, em 2021.

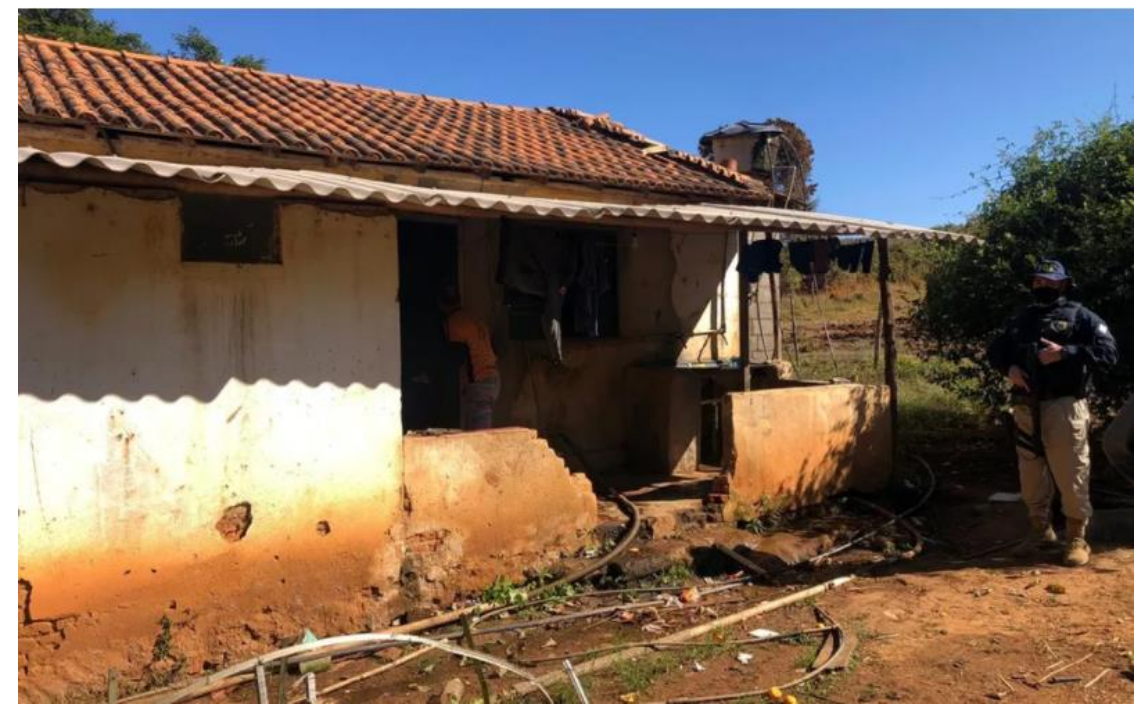

Fonte: EPTV-Sul de Minas (2021).

Infelizmente, é comum que os empregados desconheçam os seus direitos trabalhistas e, mesmo os conhecendo, costumam ser ameaçados brutalmente, caso buscarem seus direitos ou denunciarem a situação em que estão vivendo (CONECTAS DIREITOS HUMANOS, 2018, n. p).

As reportagens demonstram que mais do que um crime legislativo a escravidão contemporânea na cafeicultura da região também fere direitos, valores, bens, princípios humanos individuais e coletivos de apanhadores de café. Esses trabalhadores quando escravizados são sujeitos a condições precárias de habitações seja no não fornecimento de água potável ou então no padrão alimentar negativo, na falta de higiene e na ausência de descansos, os privando da dignidade, não os tratando como humanos, mas como uma mercadoria descartável que pode ser facilmente substituída.

\section{A ATUAÇÃO DO ESTADO NO COMBATE A ESCRAVIDÃO CONTEMPORÂNEA NOS CAFEZAIS DA REGIÃO}

De acordo com o Código Penal 149 (atualizado pela lei $n^{\circ} 10.803$, de 
11.12.2003), o crime de trabalho escravo contemporâneo impõe ao infrator diferentes sanções: a reclusão de dois a oito anos e o pagamento de multas administrativas. A pena de reclusão para aqueles que escravizam varia de 2 (dois) a 8 (oito) anos, podendo ser aumentada pela metade se o crime for cometido com crianças ou adolescentes, ou então for praticado por preconceitos relacionados a raça, cor, etnia e religião (BRASIL, 2003).

As multas administrativas são aplicadas pelo Grupo Especial de Fiscalização Móvel, responsável por coordenar operações de fiscalizações e resgastes no enfrentamento ao trabalho escravo contemporâneo em espaços rurais e urbanos no país. Esse grupo está vinculado à Secretaria de Inspeção do Trabalho, em Brasília e integrado com o Secretaria do Trabalho, Polícia Federal e demais órgãos estatais (CAVALVANTI, 2020).

Além dessas penalizações, o autor supracitado faz referências a outras políticas repressivas a essa crime, como a inclusão do nome na "lista suja" do trabalho escravo (cadastro nacional onde é registrado o nome de empregadores que escravizaram seus empregados); o pagamento de verbas trabalhistas, fundiárias e previdenciárias relativas ao período que durou a escravidão das vítimas; a indenização pelo dano moral individual e coletivo de trabalhadores; a perda de propriedade, a partir da Emenda $n^{\circ} 81$ de 2014, que estabelece a expropriação de imóveis quando for constatado o trabalho escravo (os imóveis que se localizarem em áreas rurais serão destinados a Reforma Agrária e os imóveis que se localizarem em áreas urbanas serão destinados a Programas de Habitação Popular); e restrições comerciais decorrentes do Pacto Nacional pela Erradicação do Trabalho Escravo, que impõe o isolamento comercial daqueles que exploram e escravizam trabalhadores.

No caso específico da cafeicultura do Sul/Sudoeste de Minas, a inclusão na "lista suja" de nomes de produtores de café que escravizam trabalhadores é uma das principais medidas que vem sendo tomada pelo Estado no combate a essa 
forma de exploração empregatícia. Além do cadastro de nomes de proprietários na "lista suja", o pagamento de multas e demais débitos relacionados à direitos trabalhistas e previdenciários também são deliberações punitivas e reparatórias cobradas de proprietários que escravizam em lavouras de café na região. Exemplo disso foi o pagamento de multas trabalhistas e de três parcelas do seguro desemprego que um produtor de café em Machado - MG teve que pagar por escravizar 13 trabalhadores de café na safra de 2020. Os empregados escravizados nessa fazenda trabalhavam na lavoura sem estarem assegurados por direitos trabalhistas (sem registro empregatício nas carteiras de trabalho, sem remuneração salarial), trabalhavam sem equipamentos de proteção individual e ainda viviam em alojamentos precários (EPTV- SUL DE MINAS, 2020).

Apesar das medidas de fiscalizações e penalizações existem muitos empecilhos e retrocessos (estabelecidas pelo próprio Estado brasileiro) que dificultam o combate dessa forma de exploração subumana na cafeicultura da região ( e em demais atividades empregatícias do país), como o corte de verbas que os grupos de fiscalizações vêm sofrendo desde de 2017, gerando um déficit no número de auditores fiscais do Ministério do Trabalho e de veículos para que possam realizar fiscalizações aos locais denunciados pela suspeita de trabalho escravo em cafezais da região, como evidenciou Jorge Ferreira dos Santos, coordenador da Adere-MG (Articulação dos Empregados Rurais do Estado de Minas Gerais) em uma entrevista concedida a jornalista Dotta (2018) no site de notícias Brasil de Fato.

Vale ressaltar também que a reforma trabalhista sancionada em 13 de julho de 2017, dificulta ainda mais a situação da escravidão contemporânea no país, sobretudo, na cafeicultura do Sul/Sudoeste de Minas. A reforma traz mudanças na CLT (Consolidação das Leis de Trabalho), que afetam diretamente o combate a esse crime, dentre elas, a contratação sem restrições, a ampliação do trabalho terceirizado e o aumento da jornada de trabalho. Sendo assim, esta reforma faz 
com que a legislação banalize o trabalho escravo em diversos setores e o que a própria legislação caracteriza como trabalho escravo: a servidão por dívida, condições exaustivas e esgotantes de trabalho e trabalho forçado (MAGALHÃES, 2017).

Toda esta problemática vem se agravando cada vez mais com a crise econômica provocada pandemia da COVID-19 (cujo vírus está presente em nosso país desde o mês de março de 2020), proliferada e interiorizada no Sul de Minas Gerais desde maio de 2020 (MORAES, 2020). Tal situação intensifica ainda mais, a precariedade no trabalho sazonal de apanhadores de café, sobretudo, a escravidão de trabalhadores neste setor, pois migrações aliciadas estão ocorrendo livremente, dentre tantas outras fraudes neste setor empregatício como a não utilização de EPI (Equipamentos de Proteção Individual) - que, por conta da pandemia deveria incluir também máscaras e álcool em gel para higienização das mãos - e trapaças no pagamento ( SANTOS; SANTOS, 2020).

Dessa forma, o que estamos vivenciando nessa crise sanitária e pandêmica na cafeicultura na região é a intensificação da desvalorização do trabalho de apanhadores (as) com o aumento exorbitante do trabalho informal e exploratório, o que fortalece ainda mais o uso da mão de obra escrava neste setor empregatício da região, em pleno século XXI.

\section{CONSIDERAÇÕES FINAIS}

A reestruturação produtiva da cafeicultura no Sul/Sudoeste de Minas à serviço do capital, a partir da década de 1970, acompanha o processo de modernização da agricultura brasileira, sendo um movimento de expansão territorial do capitalismo na região para a criação de novas condições de acumulação.

Mais do que um arranjo espacial com relações de classes herdadas a partir 
de condições históricas que violam direitos humanos e trabalhistas, o trabalho escravo contemporâneo na cafeicultura sul/sudoeste mineira, alimenta os meios de acumulação capitalista integrado à lógica essencial do sistema moderno e atual de muitos estabelecimentos agrícolas e industriais. Combater o trabalho escravo contemporâneo na região e nas demais partes do país fere e interfere interesses econômicos dessa cadeia produtiva. Resgatar trabalhadores escravizados é uma tarefa emergencial do Estado, no entanto, é necessário atacar o sistema que nutre a escravidão, através de criações e manutenções de políticas públicas para as minorias do país.

Dessa forma, é imprescindivel a garantia de emprego decente, moradia, saúde, educação, lazer, alimentação e reforma agrária para a população mais pobre, sobretudo, aos trabalhadores rurais volantes em seus locais de origem, que migram para o Sul/ Sudoeste de Minas a cada safra e são em sua grande maioria vítimas da precareidade e escravidão nesse setor empregatício.

\section{AGRADECIMENTOS}

Agradecimento ao apoio da agência de fomento acadêmico Fundação de Amparo à Pesquisa do Estado de Minas Gerais - FAPEMIG.

\section{REFERÊNCIAS BIBLIOGRÁFICAS}

ALVES, F. D. O rural - urbano nas cidades pequenas no sul de Minas Gerais. In:XVII ENCONTRO NACIONAL DE GEÓGRAFOS: A CONSTRUÇÃO DO BRASIL: GEOGRAFIA, AÇÃO POLÍTICA E DEMOCRACIA, 2016, São Luís. Anais. São Luís: Universidade Estadual do Maranhão (UEMA), 2016. p. 1-10. Disponível em: 1468283701_ARQUIVO_artigoengflamarion.pdf (agb.org.br). Acesso em: 11 ago. 2021.

ALVES, F. D. O Agronegócio do café e a territorialização no Sul de Minas Gerais. In: 
ALVES, F. D.; AZEVEDO, S. C. de. COCA, E. L. F. de. VALE, A. R. do. (orgs.). A dimensão política no espaço: Conflitos e desigualdades territoriais na sociedade contemporânea. Alfenas, Unifal-MG, 2019. p. 306-323. Disponível em: https://www.unifal-mg.edu.br/bibliotecas/system/files/imce/a-dimensao-politicano-espac3a7o_alves-et-al.pdf. Acesso em: 11 ago. 2021.

BALANÇA COMERCIAL DO AGRONEGÓCIO BRASILEIRO. Balança comercial de fevereiro de 2021. Disponível em: https://www.cnabrasil.org.br/assets/arquivos/boletins/Balanca-

Comercial_fevereiro2021.pdf. Acesso em: 16 mai. 2021.

BRASIL. Lei $n^{\circ} 10.803$, de 11 de dezembro de 2003. Altera o art. 149 do Decreto lei $n^{\circ} 2.848$, de 7 de dezembro de 1940- Código Penal, para estabelecer penas ao crime nele tipificado e indicar as hipóteses em que se configura condição análoga à de escravo Diário Oficial da União: seção 1. Brasília, DF, p. 1, 11 dez. 2003.

CAVALCANTI, T. M. Como o Brasil enfrenta o trabalho escravo contemporâneo. In: SAKAMOTO, L (org.). Escravidão Contemporânea. São Paulo: Contexto, 2020. p. 6784.

CECAFÉ - Conselho dos exportadores de café do Brasil. Relatório Mensal: junho de 2021. Disponível em: https://www.cecafe.com.br/publicacoes/relatorio-deexportacoes/. Acesso em: 06 ago. 2021.

COALIZÃO DO CAFÉ (org.). Café: vida, produção e trabalho - agricultores familiares e assalariados rurais. $2004 . \quad$ Disponível em: http://www.observatoriosocial.org.br/download/cafe_maio2004BX.pdf. Acesso em: 27 dez. 2019.

CONAB - Companhia Nacional de Abastecimento. Boletim da Safra de Grãos. Acompanhamento da safra brasileira de café - Safra 2020, n. 4, v. 6- Quarto levantamento, Brasília, p. 1-45, dezembro 2020.Disponível em: 
https://www.conab.gov.br/info-agro/safras/graos/boletim-da-safra-de-graos Acesso em: 11 mai. 2021.

CONDIÇÕES DE TRABALHO NA COLHEITA DE CAFÉ - ESCRAVO NEM PENSAR.RÉPORTER BRASIL. Repórter Brasil, São Paulo, 27, nov., 2019. Disponível em: https://escravonempensar.org.br/biblioteca/condicoes-do-trabalho-nacolheita-do-

cafe/\#: :text=Al\%C3\%A9m\%20disso\%2C\%20fraude\%20no\%20pagamento,cen\%

DOTTA, R. Trabalho escravo no sul de Minas: 15 foram resgatados em fazenda de café. Brasil de fato, Belo Horizonte, 10, agosto, 2018. Disponível em: https://www.redebrasilatual.com.br/trabalho/2018/08/trabalho-escravo-no-sulde-minas-15-foram-resgatados-em-fazenda-de-cafe/. Acesso em: 12 jan. 2020.

FREDERICO, S. Globalização, competitividade e regionalização: a cafeicultura científica globalizada no território brasileiro. GEOUSP Espaço e Tempo (Online), v. 18, n. 1, p. 55-70, abr., 2014. Disponível em: https://www.revistas.usp.br/geousp/article/view/81077. Acesso em: 7 jul. 2021.

G1. Mais de 60 pessoas são resgatadas em situação de trabalho escravo em lavouras cafeeiras do Sul e Minas. 21 jun. 2021. Disponível em: https://g1.globo.com/mg/sul-de-minas/noticia/2021/07/21/mais-de-60-pessoassao-resgatadas-em-situacao-de-trabalho-escravo-em-lavouras-cafeeiras-do-sulde-minas.ghtml. Acesso em: 08 dez. 2021.

G1. Operação flagra trabalho escravo em fazenda de café e resgata servidores em Machado, MG. 23 jul. 2020. Disponível em: https://g1.globo.com/mg/sul-deminas/noticia/2020/07/23/operacao-flagra-trabalho-escravo-em-fazenda-decafe-e-resgata-servidores-em-machado-mg.ghtml. Acesso em: 08 dez. 2021. IBGE. Instituto Brasileiro de Geografia e Estatística. Censo Demográfico, 2010. Disponível em: https://sidra.ibge.gov.br/Tabela/608\#resultado. Acesso em: 22 
abr. 2021.

IBGE. Instituto Brasileiro de Geografia e Estatística. Produção Agrícola Municipal Sul/Sudoeste de Minas Gerais. Rio de Janeiro, 2021. Disponível em: https://sidra.ibge.gov.br/Tabela/1613\#resultado. Acesso em: 22 abr. 2021.

LEMOS JÚNIOR, C. B. A implantação da usina hidrelétrica de Furnas (MG) e suas repercussões: Estudo sobre a Territorialização de Políticas Públicas. 2010. $129 f$. Dissertação (Mestrado em Geografia) - Instituto de Geociência, Universidade Estadual de Campinas, Campinas, 2010. Disponível em: http://www.bibliotecadigital.unicamp.br/document/?code=000778319\&fd=y. Acesso em 08 jul. 2021.

MAGALHÃES, A. Reforma trabalhista dificulta combate ao trabalho escravo. Carta Capital, São Paulo, 11, agosto, 2017. Disponível em: https://www.cartacapital.com.br/sociedade/reforma-trabalhista-dificultacombate-ao-trabalho-escravo/. Acesso em: 06 mai. 2020.

MORAES, L. Coronavírus em MG: aumento de casos no interior preocupa autoridades na capital. O tempo, Belo Horizonte, 25, maio, 2020. Disponível em: https://www.otempo.com.br/cidades/coronavirus-em-mg-aumento-de-casos-nointerior-preocupa-autoridades-na-capital-1.2341923. Acesso em: 21 jul. 2020.

OLIVEIRA, A. U. Mundialização da Agricultura Brasileira. 1 ed. São Paulo: landé Editorial, 2016.

PORTAL DE INSPEÇÃO DO TRABALHO. Radar - SIT: Painel de Informações e Estatísticas da Inspeção do Trabalho no Brasil (Trabalho Escravo). Disponível em: https://sit.trabalho.gov.br/radar/. Acesso em: 5 jul.2021.

SAKAMOTO, L. O trabalho escravo contemporâneo. In: SAKAMOTO, L. (org.). Escravidão Contemporânea. São Paulo: Contexto, 2020. p. 7- 16.

SANTOS, A. P.; SANTOS, J. F. A precarização no trabalho da cafeicultura do Sul de Minas em tempos de pandemia COVID-19. Youtube, 15 jul. 2020. Disponível em: 
https://www.youtube.com/watch?v=zfla9vO6odw. Acesso em: 18 jun. 2020.

SECRETARIA DO TRABALHO. Portaria Interministerial MTPS/MMIRDH $\mathrm{n}^{\circ} 4$ de 11/05/2016. Cadastro de Empregadores que tenham submetido trabalhadores a condições análogas à de escravo, 2018. Disponível em: https://reporterbrasil.org.br/wp-

content/uploads/2018/04/CADASTRO_DE_EMPREGADORES_2018-04-

10_publicacao_semestral_ordinaria_DETRAE_abril-2018.pdf. Acesso em: 28 abr. 2021.

SECRETARIA DO TRABALHO. Portaria Interministerial MTPS/MMIRDH $\mathrm{n}^{\circ} 4$ de 11/05/2016. Cadastro de Empregadores que tenham submetido trabalhadores a condições análogas à de escravo, 2019. Disponível em: https://d37iydjzbdkvr9.cloudfront.net/arquivos/2019/01/21/cadastro-deempregadores-2019-1-17.pdfAcesso em: 28 abr. 2021.

SECRETARIA DO TRABALHO. Portaria Interministerial MTPS/MMIRDH $\mathrm{n}^{\circ} 4$ de 11/05/2016. Cadastro de Empregadores que tenham submetido trabalhadores a condições análogas à de escravo, 2021. Disponível em: https://www.gov.br/trabalho/pt-br/inspecao/areas-deatuacao/cadastro_de_empregadores.pdf. Acesso em: 13 jul. 2021.

SILVA, S. M.; SANTOS, A. C.; LIMA, J. B. Competitividade do agronegócio do café na região Sul de Minas Gerais. Organizações Rurais e Agroindustriais. Lavras: UFLA, v. 3, n. 1, (não há páginas), jan. /jun. 2001. Disponível em: http://revista.dae.ufla.br/index.php/ora/article/view/276/273. Acesso em: 28 jun. 2021.

SILVEIRA, M. A.; MARQUES, P. E. M. Desenvolvimento territorial e multifuncionalidade da cafeicultura familiar no Sul de Minas Gerais. In: CAZELLA, A. A.; BONNAL, P.; MALUF, R. S. (org.) Agricultura familiar: multifuncionalidade e desenvolvimento territorial no Brasil. Rio de Janeiro: Mauad X, 2009, p. 229-250. 
Disponível em: https://www.embrapa.br/busca-de-publicacoes//publicacao/49240/desenvolvimento-territorial-e-multifuncionalidade-dacafeicultura-familiar-no-sul-de-minas-gerais. Acesso em: 23 mar. 2021.

TRABALHO ESCRAVO DE FAZENDAS DE CAFÉ EM MG É DENUNCIADO NA OCDE. Conectas Direitos Humanos, São Paulo, 4, nov., 2018. Seção: Desenvolvimento e direitos socioambientais. Disponível em: https://www.conectas.org/noticias/trabalho-escravo-cafe-minas-gerais-ocde. Acesso em: 27 dez. 2019.

VALE, A. R.; CALDERARO, R. A. P.; FAGUNDES, F. N. A cafeicultura em Minas Gerais: estudo comparativo entre as regiões Triângulo Mineiro/Alto Paranaíba e Sul/Sudoeste. Campo-Território. Edição especial do XXI ENGA- 2012, v.9 n. 18, p. 123. 2014. Disponível em: http://www.seer.ufu.br/index.php/campoterritorio/article/view/26933/14626. Acesso em: 28 abr. 2021.

VALE, A. R. A agricultura familiar no contexto do agronegócio do café no Sul/Sudoeste de Minas: variações sobre o mesmo tema. In: FERREIRA, M. F. M.; VALE, A. R. (Orgs.). Dinâmicas geográficas no Sul de Minas Gerais. Curitiba: Apris, 2017, p. 8-27.

VILELA, P. S.; RUFINO, J. L. S. (Org.) Caracterização da cafeicultura de montanha de Minas Gerais. Belo Horizonte: INAES, 2010 (Estudos INAES. Cadeias Produtivas. Café; 1). Disponível em: http://www.sapc.embrapa.br/arquivos/consorcio/livros/livro_cafeicultura_de_mo ntanha.pdf. Acesso em: 28 jun. 2021. 